\title{
LITERATURA E RAP NA/DA PRISÃO
}

\section{Bruno Gonçalves Zeni ${ }^{1}$}

Resumo: Dentre os livros de teor literário sobre a prisão lançados no Brasil na última década, destacam-se alguns que se relacionam com a música rap. Nesses livros, como Diário de um detento (2001), de Jocenir, e Sobrevivente André du Rap (2002), de André du Rap, o rap aparece como elemento de identificação e recurso de comunicação com o leitor. Em situação análoga, grupos de rap como Comunidade Carcerária, Detentos do Rap e 509-E produziram composições sobre a cadeia. Os Racionais MCs, apesar de não terem passado pela experiência do cárcere, têm importantes músicas sobre o tema, como "Diário de um detento" (1997), sobre o Massacre do Carandiru (1992). Analisam-se neste artigo textos da literatura prisional recente e composições de rap em que a cadeia, o crime e o próprio rap são elementos de caracterização de personagens e de estabelecimento de um público, leitor ou ouvinte, que se pretende atingir.

Palavras-chave: literatura prisional; música rap; crime; literatura de testemunho

Abstract: Among the books of literary content about prision released in Brazil in the last decade, there are some that relate to rap music. In these narratives, such as Diário de um detento (2001), by Jocenir, and Sobrevivente André du Rap (2002), by André du Rap, rap appears as an element of identification with the reader. On the other hand, rap groups like Comunidade Carcerária, 509-E and Detentos do Rap have written songs about the experience of detention. Racionais MCs, one of the best Brazilian rap groups, although its members have never been arrested, have important songs on the subject, like "Diário de um detento" (1997), a narrative about the terrible historic event known as "Massacre do Carandiru" (1992). This article analyses literary texts and rap songs where jail, crime and rap music itself are elements of formal construction and literary strategy of attracting cultivated readers and a more general public that is intended to be achieved.

Keywords: prision literature; rap music; crime; testimony

1 Doutor em Teoria Literária e Literatura Comparada pela USP. Atua na área de jornalismo e formação de escritores.

E-mail: brunozeni2016@gmail.com

Literatura e Autoritarismo, Santa Maria, n. 31: A experiência do confinamento, jan.-jun. 2018, p. 111-122. - ISSN 1679-849X 
Nas últimas três décadas muitas narrativas sobre a experiência do cárcere e sobre a vida no sistema penitenciário brasileiros expressaram as condições degradantes e violentas das cadeias, prisões e centros de detenção do país. Os relatos em livro ganharam grande impulso depois do sucesso de Estação Carandiru, de Drauzio Varella, lançado em 1999. Antes disso, a música rap já vinha produzindo depoimentos e canções sobre esse universo e sobre a relação entre a vida no cárcere e a vida nas periferias brasileiras, entre prisão e liberdade, cadeia e mundão, o "crime" e o "certo". As relações entre rap, crime e cadeia são muito íntimas e indicam que tal gênero musical é apropriado para expressar essa experiência traumática e, infelizmente, muito comum na vida de certa parcela da sociedade brasileira.

Aqui nos interessa examinar como a literatura prisional e o rap vêm elaborando formas de expressão que não apenas retratam a vida na cadeia, mas indicam uma dinâmica de tensões entre identidades, modos de se inserir socialmente e de se posicionar no universo da cultura e das artes.

$\mathrm{Na}$ literatura que aborda a vida na cadeia, os relatos se pautam por uma necessidade de contar a própria história, de atestar a sua veracidade e de revelar uma realidade que o público leitor instruído não conhece - ou conhece apenas parcialmente. No rap, os autores e cantores assumem diferentes identidades (sobrevivente, guerreiro, sangue-bom, rapaz comum, preto, poeta), e o modo de se colocar em relação a seu público marca uma posição dupla: forte identidade com um grupo social e de identidade racial (os manos, os parceiros, os pretos, os sangue-bons), assim como uma marca de alteridade bem delineada, e em muitos casos agressiva e acusatória, contra polícia, playboys, negros limitados e outros traíras.

No rap, sobressai a recorrência com que os grupos e seus cantores (ou MCs) se definem e se congratulam como rappers, como se o rap fosse um caminho de salvação ou de distanciamento em relação ao mundo do crime, especialmente de afastamento das drogas. No entanto, é também forte a identificação dos rappers com a figura do criminoso e com o mundo do crime (ou com a "vida loka", como diz uma conhecida música dos Racionais MCs).

Em São Paulo, em particular, é na identidade com o ladrão (o “artigo 157”, isto é, o praticante de roubo) que o rapper irá encontrar correspondência mais frequente, ecoando uma ambígua condição de coragem, irreverência, violência e subversão que faz dessa espécie de máscara ou persona ficcional - o ladrão - um poderoso artifício de construção literária e musical.

Se o tráfico não é defensável - ou é atividade pouco digna de orgulho - e o consumo de drogas é visto como uma prática condenável e letal, ${ }^{2}$ por outro lado os crimes contra o patrimônio, isto é, roubo e o assalto, são vistos quase como uma identidade inescapável do detento, do bandido e, algumas vezes, também do rapper.

Não se trata aqui, de reafirmar o estigma de música violenta, de bandido ou criminoso que o rap ainda carrega, mas de refletir sobre a maneira como os escritores e, especialmente, os rappers passaram a se apropriar desse estigma e usar a identidade de ladrão como um trunfo, como índice de identidade de grupo e de oposição aos que estão contra esse gênero musical, ao que se colocam contra a população marginalizada e contra a periferia. ${ }^{3}$

2 "Droga, viagem sem volta, você vai cair", diz uma letra do grupo Comunidade Carcerária. E a música dos Racionais "Diário de um detento" alerta: "Se tiver usando droga tá ruim na minha mão".

3 Laeticia Jensen Eble (2013) já chamou a atenção para essa inversão com que os rappers operam para mudar a perspectiva e questionar os estereótipos ligados ao universo da violência, da pobreza e da marginalidade. 
No rap, além disso, a identidade de ladrão é elemento de caracterização forte, que faz com que algumas letras ganhem um caráter ficcional acentuado, promovendo um jogo de lusco-fusco entre rapper e bandido que é, do ponto de vista artístico e musical, muito poderoso, pois envolve também o ouvinte, e que, do ponto de vista ético, propõe uma apropriação e uma reconstrução autoral e digna da identidade de marginal: não a de bandidão sem consciência, mas a de "guerreiro de fé", "terrorista da periferia", uma identidade de quem vive o "negro drama", isto é, o drama de "cadeia e favela", como diz "Negro drama", um dos grandes sucessos dos Racionais.

Se no rap essa ambiguidade é parte da performance de letra e música, que envolve e confunde rapper, personagem e público ouvinte, na literatura o jogo é talvez menos evidente, mas também é constitutivo dessa produção e da posição social e artística de seus autores.

\section{PASSAGENS (LITERÁRIAS) PELA CADEIA}

Em São Paulo, a produção de literatura prisional tornou-se uma espécie de nicho editorial no começo da década passada. Alguns desses relatos fizeram bastante sucesso e tiveram grande repercussão midiática. Depois de Estação Carandiru (1999), que foi pioneiro e abriu caminho para esse filão, alguns detentos e ex-detentos passaram também a escrever e ser publicados por grandes editoras brasileiras, como Companhia das Letras, Geração Editorial e por editoras menores, como a Labortexto. Esta última, que já encerrou atividades, como que se especializou no tema. ${ }^{4}$

Como afirma o trabalho de Maria Rita Palmeira (2009) sobre a literatura prisional brasileira das últimas décadas, a escrita desses autores apoia-se em uma ambiguidade constitutiva, que é a de escrever para um público leitor amplo, que não passou pela experiência do cárcere, um público que se quer atingir e conquistar. Por outro lado, é grande o esforço de provar o pertencimento ao mundo do cárcere, de sublinhar o caráter testemunhal de seus relatos e há também a necessidade de permanecer fiel e leal aos preceitos e princípios do mundo da prisão.

O estigma de ladrão é índice dessa ambiguidade. Como lembra Maria Rita Palmeira, a incorporação da identidade de ladrão é uma forma de se apropriar do estigma, mas que não se desvencilha das armadilhas da identificação com o grupo, por um lado, e da diferenciação excessiva desse mesmo universo, por outro. Diz a autora: "A incorporação do estigma e a necessidade de se livrar dele remontam ao olhar duplo, que ora aponta para dentro da cadeia, ora para fora dela". ${ }^{5}$ Assim, o risco que essa "ambivalência de identidade" (Goffman) acarreta é, ao olhar muito para fora da cadeia, identificar-se não com os iguais, mas com os inimigos (a polícia, os playboys e os traidores da causa).

\footnotetext{
4 A Companhia das Letras, além de Estação Carandiru, de Drauzio Varella, lançou Memórias de um sobrevivente, de Luiz Alberto Mendes. A Geração Editorial publicou Pavilhão 9: paixão e morte no Carandiru, de Hosmany Ramos, e Vidas do Carandiru: histórias reais, de Humberto Rodrigues. Saíram pela Labortexto: Quatrocentos contra um: uma história do Comando Vermelho, de William da Silva Lima, Diário de um detento, o livro, de Jocenir, e Sobrevivente André du Rap (do Massacre do Carandiru), que publiquei com José André de Araújo.

5 PALMEIRA, Maria Rita Sigaud Soares. Cada história, uma sentença: narrativas contemporâneas do cárcere brasileiro. Tese (Doutorado) em Literatura Brasileira. Departamento de Letras Clássicas e Vernáculas. Universidade de São Paulo, 2009, p. 159.
} 
A identidade com o crime de furto ou roubo é aquela que mais sobressai nos relatos de Luiz Alberto Mendes, Jocenir e André Du Rap. No caso deste último, a identificação como ladrão, que marca seu relato desde o princípio, é ainda mais significativa, já o crime pelo qual ele foi condenado não foi esse, mas o de homicídio. Em seu relato, detento e ladrão são palavras que muitas vezes se equivalem. No impactante capítulo sobre o Massacre do Carandiru, em que narra os acontecimentos que antecederam imediatamente a ação da polícia, ao se referir à briga entre dois detentos do pavilhão 9 que teria sido o estopim para a rebelião que a polícia reprimiu com violência desmedida, André du Rap diz que a confusão deveria ter sido resolvida entre os próprios presos, mas que os funcionários decidiram intervir. A frase que resume essa convicção é: "Treta de ladrão é treta de ladrão". ${ }^{6}$ No mesmo capítulo, quando a polícia dá ordens aos detentos sobreviventes, é também de "ladrão" que os PMs chamam os presos. Diz o relato: "Vai ladrão, vai, zé, corre, filho da puta - não chamavam a gente por nome não, era só 'zé', 'ladrão', xingando de 'filho da puta'."' A identidade de ladrão, portanto, vem dos próprios presos, mas se confirma também, de maneira relacional, na maneira com que os policiais (e também os funcionários das cadeias) se referem aos detentos.

A narrativa de André du Rap concentra-se no período que ele passou na cadeia (mais de dez anos preso). Já o relato de Luiz Alberto Mendes explora de maneira mais tradicional o gênero autobiográfico. Seu romance tem início com alguns capítulos sobre a infância, sobre a relação difícil com o pai alcoólatra, sobre outros problemas familiares. Ele narra o hábito de furtar e roubar desde que ele tinha nove anos, a começar dos furtos que fazia do dinheiro de seus próprios familiares. Depois de realizar o seu primeiro feito, o de furtar o que ele imagina ser uma arma de verdade da vitrine de uma relojoaria (que ele viria a descobrir que era um isqueiro em formato de revólver), diz ele: "Depois dessa façanha, o respeito cresceu enormemente. E isso era tudo o que eu queria: ser famoso e temido". A seguir narra como sua necessidade de capital cresceu, pois passou a "comprar" suas relações, como, por exemplo, ao pagar sorvetes e doces para as meninas e levá-las ao cinema. Assim como André du Rap, Mendes irá confessar ao leitor outros crimes, entre eles dois assassinatos, mas é o crime de assalto e furto aquele que está, segundo a narrativa construída por ele próprio, na origem de sua vida "no crime". Como já afirmou Marcio Seligmann-Silva (2006), o roubo é também o crime que permite legitimar a malandragem e sua inserção na bandidagem, no grupo de iguais: os outros ladrões. ${ }^{9}$

Aos leitores acostumados com a ficção, esse impulso aventuresco soa familiar. É como se o mito do bom ladrão e do banditismo social (Hobsbawm), em sua versão urbana e pós-industrial, persistisse como uma moldura literária que justifica tanto o desejo de aventura como também, como uma fatalidade, o descaminho. Aventura, e certa nobreza ligada à ação, é o que o assalto e os crimes de furto e roubo parecem assegurar àqueles que pretendem conferir a suas trajetórias justificativas artísticas e morais, afirmando-se como escritores, e

6 DU RAP, André. Sobrevivente André du Rap (Do Massacre do Carandiru). Coordenação editorial de Bruno Zeni. São Paulo: Labortexto Editorial, 2002, p. 18.

7 Idem, ibidem. p. 22.

8 MENDES, Luiz Alberto. Memórias de um sobrevivente. São Paulo: Companhia das Letras, 2001, p. 23.

9 SELIGMANN-SILVA, Marcio. "Novos escritos dos cárceres: uma análise de caso. Luiz Alberto Mendes, Memórias de um sobrevivente”. Estudos de Literatura Brasileira Contemporânea, n. 27, 2006. 
assim ultrapassando sua condição de criminosos comuns, apenados, detentos, ex-presidiários. Com isso, os detentos escritores encontram sentido mais amplo para suas experiências, tanto antes da prisão como durante o cárcere. As condenações, por sua vez, são atenuadas em seu conteúdo moral, ganhando mais peso do ponto de vista jurídico e social. Aliado a isso, isto é, ao novo sentido dado à experiência da condenação e da pena, também as forças da ordem, sobretudo em seu braço policial, são elementos que ganham relevo. É recorrente o confronto com os policiais, que assumem invariavelmente o papel de antagonistas, de inimigos e de vilões (no que, aliás, conhecendo a atuação da polícia brasileira, pautada via de regra pelo desrespeito aos direitos, os autores estão cobertos de razão).

O livro de Jocenir, Diário de um detento (2001), é eloquente a esse respeito. O autor começa o relato, significativamente, com um capítulo que pretende revelar ao leitor como é a vida no interior das prisões. O retrato que ele pinta é o de um amontoado de homens rendidos às drogas, especialmente ao crack. Impressionam as repetições em torno desse tema e a quantidade de vezes em que ele fala de drogas, dependência e termos similares no capítulo inicial, para depois, no capítulo seguinte, narrar a cinematográfica ação policial (criminosa) na qual ele foi envolvido, de gaiato, como participante. Nela, acabou sendo preso e responsabilizado injustamente por receptação de carga roubada (sob coação, Jocenir assume a sua responsabilidade no crime para livrar a culpa dos policiais, que eram os verdadeiros bandidos na situação tal como descrita pelo autor).

Outro elemento importante de seu relato é a letra do rap "Diário de um detento", que dá título ao livro, está reproduzida ao final do volume e à qual é dedicada um capítulo em que se narra a visita de Mano Brown ao Carandiru, quando escritor e rapper se conheceram. Voltaremos a esse rap, ao comentar as letras dos Racionais MCs.

\section{COMUNIDADE NO CÁRCERE}

A extinta Casa de Detenção de São Paulo, conhecida como presídio do Carandiru, assim como o local de onde saíram os principais relatos literários recentes, é também prisão onde se encontram exemplos de formação de grupos de rap e de produção de raps que falam da cadeia e do mundo do crime. No Carandiru, formaram-se os grupos Detentos do Rap, em 1996, no pavilhão 6; 509-E, em 1999, na cela de mesmo número do pavilhão 7; e Comunidade Carcerária, que existia desde 1996, mas gravou o primeiro disco no ano 2000. Como acontece nos relatos literários, a identidade de ladrão aparece com força também no rap desses grupos. ${ }^{10}$

No caso do Comunidade Carcerária, como indica o nome do grupo, a identidade coletiva com a massa de presidiários é constitutiva de sua formação. As duas músicas mais conhecidas do grupo, "Código de honra" e "Oitavo Pavilhão", também definem os cantores como seguidores de um código de conduta afinado às regras da cadeia, isto é, ao "proceder" dos detentos. "Oitavo Pavilhão" estabelece ainda o pavilhão onde o grupo se formou como lugar forte de pertencimento, assim como ocorre com os grupos de rap, que cantam,

10 Sobre os grupos 509-E e Detentos do Rap, ver o trabalho de Carla Cristiane Mello. Vozes do Carandiru: o rap de cárcere e os estigmas sociais. Dissertação (Mestrado). Centro de Comunicação e Expressão. Programa de Literatura. Universidade Federal de Santa Catarina. Florianópolis, 2015. 
orgulhosamente, a sua quebrada. O refrão da primeira música diz: “Código de honra, essa é a nossa voz, Comunidade Carcerária somos nós, o nosso som é o hip hop, o rap é a nossa voz". O refrão da segunda é: "Oitavo Pavilhão no ar. Aqui é sangue bom, lado a lado com os irmãos”. Assim, o rap e o código de honra dos detentos são a voz do grupo, e no pavilhão em que estão (estavam, pois hoje todos os integrantes do grupo se encontram em liberdade) eles se sentem "lado a lado com os irmãos", mas "no ar", como se mesmo os ouvintes de fora da cadeia pudessem sintonizar, na rádio - essa rádio imaginária construída pelo refrão do rap - sua música e sua voz.

As letras do 509-E, formado por Dexter e Afro-X, giram quase todas elas em torno da vida no crime e na cadeia. "Detenção, pior que o Vietnam", diz a música "Oitavo anjo", do álbum Provérbios 13 (2000). No mesmo disco, "Castelo de ladrão" associa rap, vida de bandido e liberdade: "Quem ama a liberdade, vem comigo no refrão, quem ama a liberdade, faz castelo de ladrão". Em outra música da dupla, "Só os fortes", um detento (o clipe foi gravado dentro do Carandiru) começa definindo a vida e a linguagem da cadeia. Diz a letra: "Tranca é cela, olho da ventana o sol nascer quadrado". Apesar do clichê (ver o sol nascer quadrado como sinônimo de estar preso), importa notar como é decisiva a posição interna do narrador, que fala de dentro da cela. Ele diz que a cadeia é "a Lei do Cão aqui na Terra" e que tem saudade da favela. Ele se põe a contar como foi parar ali: "A BMW preta me fascinou, você pode ter uma, o diabo soprou, mundo de ilusão, o castelo caiu, DVC 157”. A sigla DVC (Divisão de Vigilância e Captura) se refere ao banco de dados da polícia sobre antecedentes criminais.

Nas músicas dos Detentos do Rap, outra banda formada no Carandiru, crime, cadeia e rap também se embaralham. "Casa de Detenção", do álbum Quebrando as algemas do preconceito (2001), faz uma descrição minuciosa do presídio, a partir do ponto de vista de um preso que vai percorrendo os pavilhões e as galerias. Outra música desse mesmo álbum, "Entrevista no Inferno", é narrada por um detento e inclui a personagem de uma repórter. A voz feminina, ao longo da música, faz algumas perguntas como "Você acha que após cumprir pena aqui na Casa de Detenção o detento é capaz de se reintegrar à sociedade?" e "Como você acha que é visto pela sociedade?". O preso então diz: "Pra sociedade, veja só como e quem eu sou. Eu sou seu pesadelo, sou medo, sou vício, sou aquela bala em direção ao seu ouvido, a neblina e a maldade que surgem na calada”. Ele se define também como "guerreiro da favela, terror da playboyzada", "mensageiro da verdade". E "psicopata na rima”, diz ele: "sou do rap, sou da rua". Apesar de estar detido, é como bandido e rapper que ele entrevê a liberdade. Ele surge "na calada" da noite, como um assaltante. E como diz a música, se ele é "do rap", é "da rua”.

Do mesmo grupo Detentos do Rap, a música "Vida bandida", do álbum Deus do morro (2005), é narrada por um homem que relembra suas ações na juventude, quando foi baleado em uma boca de tráfico, indo parar em uma UTI. A certa altura, uma voz que parece ser a de um médico ou enfermeiro anuncia a sua morte por falência múltipla de órgãos. $\mathrm{O}$ personagem então narra sua descida à sepultura e seu pós-morte (o que faz da música um caso curioso de Memórias póstumas no rap): "Que desespero tá minha família agora, saber que eu morri antes da hora (...), desce o meu caixão na funda sepultura, mais uma vítima da guerra dura". E mesmo um rap romântico do grupo como "Apenas mais um" tem como 
matéria-prima a vida na cadeia e no crime. O rapper diz que "aqui dentro" é "chamado de detento". E mais adiante: “A Detenção não valoriza ninguém, nesse sequestro somos os reféns".

Outros exemplos de grupos de rap que têm a prisão ou o crime como tema poderiam ser arrolados, em composições que valem audição e análise: de São Paulo, Facção Central; de Brasília, Gog; do Rio de Janeiro, o rapper MV Bill, para citar os mais conhecidos. No entanto, são as letras dos Racionais MCs que elevam a identidade entre rapper e ladrão, entre poeta e bandido a um nível de complexidade extraordinário do ponto de vista artístico.

\section{RACIONAIS: O RAP ENTRE O TESTEMUNHAL E O FICCIONAL}

Em algumas letras dos Racionais, a identidade de ladrão informa a construção de determinados personagens. Alguns raps do grupo feitos na década de 1990 já tomavam como matéria de narrativa a vida de detento, de ex-detento e de criminoso. Lembremos três exemplos importantes de composições que contam a história de protagonistas envolvidos com o crime: "O homem na estrada" e "Mano na porta do bar", duas faixas do álbum Raio-X Brasil (1993), e "Tô ouvindo alguém me chamar", do disco Sobrevivendo no Inferno (1997).

Uma letra mais recente é "Eu sou 157", do álbum Nada como um dia após o outro dia (2002), cujo refrão ("Hoje eu sou ladrão, artigo 157, as cachorras me amam, os playboys se derretem, a polícia bola um plano, sou herói de pivete") é cantado em um tom e com uma dramaticidade diferentes do restante da música, por meio de uma voz filtrada por uma espécie de sintetizador, o que claramente indica o artifício de opor narrador e personagem, que ora se confundem, ora se diferenciam, em uma operação de ficcionalização e de performance (ZUMTHOR) que confere à letra e à canção uma dramaticidade poderosa e altamente mobilizadora.

Feita para cantar junto mas também para pensar, marca das músicas dos Racionais (GARCIA), ela convida o ouvinte, também ele, a se identificar com o ladrão, a se dizer ladrão: "Hoje eu sou ladrão, artigo 157". Como registra Teperman (2015), Mano Brown já se mostrou preocupado com o fato de que muitas pessoas não entendem bem a "mensagem" da música. Brown deu declarações nesse sentido à revista Caros Amigos e diz que por um tempo evitou cantar as músicas nos shows do grupo. O receio do próprio rapper em ser mal-entendido, isto é, o receio de que o ouvinte entenda que se trata de um incentivo a ser ladrão ou apologia ao crime, dá a medida da ambiguidade constitutiva da composição.

Não se pode, é claro, deixar de mencionar mais uma vez "Diário de um detento", do disco Sobrevivendo no Inferno (1997), em que é o próprio detento, um detento ficcional, um detento que é narrador e personagem, sobrevivente do Massacre do Carandiru, quem narra os acontecimentos de dentro da cadeia. É, mais uma vez, como ladrão que se identifica esse eu-lírico ou narrador-protagonista, em uma passagem inicial da letra que generaliza a sua condição a todos os presos que estão ali, à mercê da polícia armada. Diz a letra:

São Paulo, dia 1 o de outubro de 1992, 8 h da manhã. Aqui estou, mais um dia. Sob o olhar sanguinário do vigia. Você não sabe como é caminhar com a cabeça na mira de uma HK, metralhadora alemã ou de Israel, estraçalha ladrão que nem pa- 
pel. Na muralha, em pé, mais um cidadão josé. Servindo o Estado, um PM bom. Passa fome, metido a Charles Bronson.

“Aqui estou mais um dia", diz a letra, deixando clara a situação de quem narra. É um detento que está preso, há algum tempo. É 10 de outubro, um dia antes do Massacre, ação que será depois narrada na letra, sob o ponto de vista desse detento. De início, ele olha o vigia, o qual porta uma metralhadora HK. Diz o detento: ela estraçalha "ladrão" que nem papel. Preso e ladrão, portanto, se equivalem, são sinônimos, e estão à mercê do arbítrio do PM, esse cidadão josé, um cidadão qualquer, alguém como ele, detento, mas que serve ao Estado, a um Estado violento como é o Estado brasileiro (e, especificamente, ao Estado paulista). O que diz esse detento sobre o PM? Diz que ele passa fome, mas é metido a Charles Bronson, o ator americano de filmes de ação, caçador de criminosos. O cinema americano, assim como a literatura de aventura, informa os modelos de façanha e audácia que presos, bandidos e policiais reconhecem como a vida: uma guerra de salve-se quem puder, em que impera a lei do cão. Daí a importância da identidade de "sobrevivente".

Do mesmo disco, Sobrevivendo no Inferno (1997), a música "Capítulo 4, versículo 3" leva essas relações de identidade a um novo e mais complexo patamar. A música tem como narrador um personagem que, inicialmente, parece ser um criminoso em plena ação. Depois da introdução da música, que apresenta uma série de estatísticas que reafirmam a vulnerabilidade da população negra, entra a voz do cantor, em ação, ameaçador, dizendo: "Minha intenção é ruim, esvazia o lugar, eu tô em cima, eu tô a fim, um, dois pra atirar. Eu sou bem pior do que você tá vendo. O preto aqui não tem dó, é 100\% veneno".

O narrador, na voz de Mano Brown, é um "negro 100\% veneno", que invade um bar, e se dirige a um interlocutor que está no local de sua ação: "Minha intenção é ruim, esvazia o lugar". O começo é uma típica cena de assalto, que poderia estar, por exemplo, em uma narrativa de Rubem Fonseca ou Marçal Aquino. Mas logo a letra vai acrescentando a essa identidade em situação a condição de rapper, poeta, versejador: "A minha palavra vale um tiro, eu tenho muita munição". E o narrador continua a perfilar uma série de identidades que ele pode assumir, imaginariamente: "Talvez eu seja um sádico, um anjo, um mágico, juiz ou réu, um bandido do céu, malandro ou otário, quase sanguinário, franco atirador se for necessário, revolucionário, insano ou marginal, antigo e moderno, imortal".

Nessa espécie de roleta-russa a que o ouvinte é exposto, o rapper faz uni-duni-tê e se pergunta: "O que eu tenho pra você? Um rap venenoso ou uma rajada de PT?". Esta composição, por meio de um "ataque cardíaco do verso", problematiza, em cena e em ação, em voz e em palavras, a dinâmica de identidade e diferenciação entre rapper e criminoso. São uma música e um rapper que se declaram capaz de confundir, de "sabotar o raciocínio", de "abalar o sistema nervoso e sanguíneo". A confusão, provavelmente se dá, ou se intensifica justamente nessa dualidade.

O que esperar desse terrorista da periferia: versos envenenados ou uma rajada de arma de fogo? Poeta e ladrão aqui são duas faces dessa mesma moeda, desse rapper que é "violentamente pacífico", que maneja um "ataque cardíaco do verso" e está na fronteira do inferno com o céu, como diz a letra.

O discurso é poderoso, ambíguo, contraditório e maravilhosamente construído: literário, ficcional, ele dissocia autor e emissor, chama a atenção para o fato de o rapper, $\mid 118$ | 
aquele que canta, ser poeta e terrorista, criando uma situação em que o ouvinte precisa se posicionar, induzindo, também ele, ouvinte, a se identificar com esse rapper camaleônico e provocador - ou reagir a ele, contrapondo-se ao discurso da composição.

Essa identidade múltipla, de poeta, rapper, ladrão, que nas composições narrativas vem formalizada em termos ficcionais - os bandidos são personagens da história contada na letra - ganha em letras mais recentes uma espécie de retorno a uma comunidade imaginária de irmãos, de manos, aquela fratria cuja constituição Maria Rita Kehl (2000) tão bem identificou como o "esforço civilizatório" do grupo na periferia de São Paulo. Em "Negro drama" e "Vida loka", o narrador da história e o cantor (aquele que a performa, isto é, aquele que dá voz e corpo a essa narrativa) ganham mais uma vez uma identificação quase que indelével com Edy Rock e Mano Brown, os cantores do grupo. Em "Negro drama”, a voz de Edy Rock fala em nome próprio (não recorre a personagens em situação para definir o drama dos negros). E em "Vida loka” é a voz de Mano Brown que encena ser ele mesmo, Mano Brown, em discussão com outro personagem, que é um traíra, um cidadão acusado, na música, de "piolhagem", isto é, de traição, de sacanagem, de ter acusado Brown injustamente. O crime de traição é, assim, pior que o crime de roubo, furto, assalto, aqueles crimes que fazem a "vida loka". Nessa música, aliás, o grupo faz um brinde a um personagem que eles celebram como "o primeiro vida loka": Dimas, o ladrão que foi crucificado ao lado de Cristo. É a ele que os cantores levantam o brinde: “A Dimas, o primeiro Vida Loka da história!”. Com isso, não quero dizer, obviamente, que os Racionais fazem uma defesa dos ladrões, do crime ou da vida loka. Na verdade, eles fazem muito melhor. Assumindo um papel elaborado, construído, de rapper e de ladrão, eles dramatizam posições sociais e éticas, a deles e a do personagem ladrão, incluindo o ouvinte nesse jogo ficcional e performático. Fazem um retrato ao mesmo tempo cru, cruel e complexo de uma sociedade que criminaliza a pobreza, a negritude e o próprio rap. Com isso, apropriam-se do estigma e o devolvem - por meio de letras inteligentes e de uma poeticidade altamente elaborada - a quem os escuta, desafiando o ouvinte.

Como diz a letra de "Negro drama", o drama é de "cadeia e favela", um drama que indica a comunicação entre esses dois espaços, uma dinâmica que o rap conhece bem e que procura, por meio de letras e de performances elaboradas, que marcam uma alteridade provocadora e uma inteligência artística notável, tornar assunto e problema de todos, e não apenas do gueto, deles próprios e de seus trutas, mas também de quem ouve e até dos que se recusam a ouvi-los. 


\section{REFERÊNCIAS}

DU RAP, André. Sobrevivente André du Rap (Do Massacre do Carandiru). Coordenação editorial de Bruno Zeni. São Paulo: Labortexto Editorial, 2002.

EBLE, Laetitia Jensen. “'A responsa de mudar o mundo com a ponta de uma caneta': considerações sobre o rap nacional”. Revista Brasileira de Estudos da Canção. Natal, n. 4, jul.-dez. 2013.

GARCIA, Walter. "Ouvindo Racionais MCs”. Teresa: Revista de Literatura Brasileira. Departamento de Letras Clássicas e Vernáculas, USP, São Paulo, n. 4/5, 2004, pp. 166-180.

GOFFMAN, Ervin. Estigma: notas sobre a manipulação da identidade deteriorada. Rio de Janeiro: Guanabara Koogan, 1988.

HOBSBAWN, Eric. Bandidos. Tradução de Donaldson Magalhães Garschagen. Rio de Janeiro: Forense Universitária, 1975.

JOCENIR. Diário de um detento: o livro. São Paulo: Labortexto Editorial, 2001.

KEHL, Maria Rita. “A fratria órfã”. In: Função fraterna. Organização de Maria Rita Kehl. Rio de Janeiro: Relume Dumará, 2000, pp. 209-244.

MELLO, Carla Cristiane. Vozes do Carandiru: o rap de cárcere e os estigmas sociais. Dissertação (Mestrado). Centro de Comunicação e Expressão. Programa de Literatura. Universidade Federal de Santa Catarina. Florianópolis, 2015.

MENDES, Luiz Alberto. Memórias de um sobrevivente. São Paulo: Companhia das Letras, 2001.

PALMEIRA, Maria Rita Sigaud Soares. Cada história, uma sentença: narrativas contemporâneas do cárcere brasileiro. Tese (Doutorado). Literatura Brasileira. Departamento de Letras Clássicas e Vernáculas. Universidade de São Paulo, 2009.

SELIGMANN-SILVA, Marcio. "Novos escritos dos cárceres: uma análise de caso. Luiz Alberto Mendes, Memórias de um sobrevivente". Estudos de Literatura Brasileira Contemporânea, Brasília, n. $27,2006$.

VARELLA, Drauzio. Estação Carandiru, São Paulo, Companhia das Letras, 1999.

TEPERMAN, Ricardo. Se liga no som: as transformações do rap no Brasil. São Paulo: Claro Enigma, 2015.

ZUMTHOR, Paul. Performance, recepção, leitura. Tradução de Jerusa Pires Ferreira e Suely Fenerich. São Paulo: Cosac Naify, 2014. 


\section{Discos de rap}

509-E. Provérbios 13 (Atração, 2000).

COMUNIDADE CARCERÁRIA. Comunidade Carcerária (Atração, 2000).

DETENTOS DO RAP. Quebrando as algemas do preconceito (Sky Blue, 2001).

Deus do morro (Sky Blue, 2005).

RACIONAIS MCs. Raio-X Brasil (Zimbabwe, 1993).

Sobrevivendo no Inferno (Cosa Nostra, 1997).

Nada como um dia após o outro dia (Cosa Nostra, 2002). 
